\title{
Cyclophosphamide in the treatment of focal segmental glomerulosclerosis
}

R. Martinelli, L.J. Pereira, O.M.M. Silva, A.S. Okumura and $\mathrm{H}$. Rocha
Serviço de Nefrologia, Departamento de Medicina, Faculdade de Medicina, Universidade Federal da Bahia, Salvador, BA, Brasil
Correspondence

R. Martinelli

Hospital Universitário, UFBA

Rua João das Botas, $\mathrm{s} / \mathrm{n}$

40110-160 Salvador, BA

Brasil

Fax: +55-71-235-8854

E-mail: rm@ufba.br

....................

Received July 22, 2003 Accepted March 11, 2004 ...................

\begin{abstract}
Prednisone is the initial treatment of primary focal segmental glomerulosclerosis. However, when immunosuppressive agents in combination with steroids are used in the treatment of prednisone-dependent and prednisone-resistant patients the remission rate is variable. We report a long-term trial using cyclophosphamide $(2.0$ to $3.0 \mathrm{mg} / \mathrm{kg}$ body weight for 12 weeks) in combination with prednisone (1.0 to 2.0 $\mathrm{mg} / \mathrm{kg}$ body weight), as compared with prednisone alone for the treatment of prednisone-resistant and frequently relapsing nephrotic syndrome and focal segmental glomerulosclerosis. Fifty-four patients (34 males and 20 females) with a diagnosis of idiopathic nephrotic syndrome and focal segmental glomerulosclerosis, followed-up for an average of $86.1 \pm 82.4$ months, were evaluated. Complete remission occurred in $20.4 \%$ and partial remission in $14.8 \%$ of the patients treated with steroids and in 26.7 and $20.0 \%$ of the patients treated with cyclophosphamide + prednisone, respectively. Of the 24 prednisoneresistant patients treated with steroids in combination with cyclophosphamide, $33.3 \%$ obtained a complete/partial response. At the time of final evaluation, $25 \%$ of the patients treated with prednisone and $10.0 \%$ of those treated with prednisone in combination with cyclophosphamide had reached end-stage renal disease. Persistent nephrotic syndrome and progressive renal insufficiency were more frequently observed among the patients treated with prednisone alone (50.0 vs $33.3 \%$ and 33.3 vs $16.7 \%$, respectively). The treatments were well tolerated and no patient experienced adverse reactions requiring discontinuation of medications. Although open-label and non-randomized, the present trial showed that cyclophosphamide is a reasonable choice for the treatment of primary focal segmental glomerulosclerosis and prednisone-resistant nephrotic syndrome.
\end{abstract}

\section{Introduction}

Focal segmental glomerulosclerosis is an important primary glomerular disease causing nephrotic syndrome and chronic renal failure in both adults and children (1-3). Although its natural course has been well described, its treatment is still a matter of debate (4-12). Prednisone is the initial treat-
Key words

- Cyclophosphamide

- Prednisone

- Nephrotic syndrome

- Primary glomerular disease

- Focal segmental

glomerulosclerosis 
are usually much lower ones than those achieved in initially prednisone-responsive patients (9,16-19).

Cyclophosphamide is a well-known cytotoxic agent used in the treatment of frequently relapsing, steroid-dependent and steroid-resistant nephrotic syndrome and of immunologic diseases with secondary glomerular involvement. Although it has been used in the treatment of focal segmental glomerulosclerosis for many years, the benefit of the combination of cyclophosphamide along with prednisone has not been fully characterized $(6,9,16-18,20,21)$. The trials have been limited, the studies have been non-randomized and open-label and the series have included small numbers of patients with a short-term follow-up.

We report an open-label, non-randomized long-term trial using cyclophosphamide in combination with prednisone, as compared to prednisone alone, for the treatment of focal segmental glomerulosclerosis and prednisone-resistant and frequently relapsing nephrotic syndrome.

\section{Subjects and Methods}

A total of 54 patients, 34 males and 20 females with a mean age of $18.6 \pm 12.9$ years (30 of them younger than 18 years) followed-up on average for $86.1 \pm 82.4$ months, were included in the present study.

All patients had a diagnosis of idiopathic nephrotic syndrome and focal segmental glomerulosclerosis and have been followed at the Renal Service of the University Hospital, University of Bahia, Salvador, BA, Brazil, for at least 6 months. All patients underwent a percutaneous renal biopsy and sections containing at least 8 glomeruli were examined by a nephropathologist, classified according to Churg et al. (22) and D'Agati (23) and characterized by a segmental area of solidification of some glomeruli. In the affected areas the capillary loops were segmentally collapsed and the capillary lumina were obliterated by matrix material, with adhesion of the tuft to the adjacent Bowman's capsule. The remainder of the capillary tuft and the unaffected glomeruli were normal in appearance. The extent of interstitial fibrosis was graded on a scale of 0,1 and 2 respectively indicating absent, mild and moderate/ severe disease.

At the time of initial evaluation a full history was taken and a physical examination performed, in addition to the following laboratory tests: urinalysis, 24-h urinary protein excretion, creatinine clearance, serum levels of creatinine, cholesterol, albumin and fasting blood glucose, and other tests to exclude systemic diseases, as appropriate. Patients diagnosed as being obese or having reflux nephropathy, HIV infection or systemic diseases that could cause renal disease were excluded.

For the purpose of the present study, patients were considered to be adults if the renal disease was diagnosed at the age $>18$ years and as children if it was diagnosed at age $\leq 18$ years. Nephrotic syndrome was diagnosed by the presence of edema, urinary protein excretion equal to or greater than 3.5 $\mathrm{g} / 24 \mathrm{~h}$ for adults or greater than $30 \mathrm{mg} / \mathrm{kg}$ body weight $/ 24 \mathrm{~h}$ for children, serum albumin below $3.0 \mathrm{~g} / \mathrm{dl}$ and serum cholesterol greater than $250 \mathrm{mg} / \mathrm{dl}$. Hypertension was defined as blood pressure above 140/90 $\mathrm{mmHg}$ in adult patients and readings exceeding the 95 th percentiles for systolic or diastolic blood pressure for age and gender, in patients younger than 12 years. Renal disease was considered to be progressive when an age-related increase in serum creatinine to levels above normal occurred during the follow-up. Renal insufficiency was defined by serum creatinine levels above 1.4 $\mathrm{mg} / \mathrm{dl}$ or the age-related normal levels and end-stage renal disease was defined as serum creatinine levels higher than $7.5 \mathrm{mg} / \mathrm{dl}$ or five times the age-related normal upper limits or by the need for dialysis therapy.

The patients were treated with 1.0 to 2.0 $\mathrm{mg}$ prednisone/kg body weight per day, di- 
vided into two to three doses for 4 to 6 weeks, followed by a single dose of prednisone on alternate days for 4 additional weeks, which was then gradually discontinued over 2 to 3 months. Remission was defined as the absence of proteinuria (complete) or reduction of proteinuria to nonnephrotic levels (partial), and resistance as the persistence of nephrotic range proteinuria during the 6 weeks of daily treatment. Relapse was defined as recurrence of the nephrotic range proteinuria after urine had been protein-free for at least 4 weeks. The occurrence of frequent relapse was defined as 3 or more relapses within 12 months in an initially steroid-responsive patient. The clinical response to prednisone was classified as: steroid responsive - complete or partial remission of proteinuria during the steroid therapy persisting for at least 8 weeks after therapy; steroid dependent - remission of proteinuria during therapy but recurrence when the dosage was reduced below a critical level or relapse of proteinuria within the first month after the end of prednisone therapy; resistant - no remission of proteinuria during 8 consecutive weeks of daily therapy.

All steroid-resistant patients and patients with frequently relapsing nephrotic syndrome $(\mathrm{N}=30)$ received a daily oral dose of 2.0 to $3.0 \mathrm{mg}$ cyclophosphamide/ $\mathrm{kg}$ body weight for 12 weeks, concurrently with the same steroid regimen. Because the addition of cyclophosphamide to the steroid regimen is a standard treatment for steroid dependent and frequently relapsing nephrotic syndrome in current practice, it was not necessary to obtain the approval of the Ethics Committee nor the written informed consent from the patients.

The clinical course and final outcome of each patient were evaluated by recording current medication, blood pressure, serum creatinine and albumin levels, urinalysis, and 24-h urinary protein excretion.

Data are reported as means $\pm \mathrm{SD}$ or as proportions. Comparisons were performed using the Student $t$-test for continuous data and the chi-square test or the Fisher exact test for categorical data, as appropriate. The renal survival curves were plotted by the Kaplan-Meier method (24). The log-rank test was used for comparison of survival curves.

Spearman correlation coefficients were calculated to examine the relationship between the variables and the development of end-stage renal disease. The analyses were two-tailed and the level of significance was set at $\mathrm{P}<0.05$ in all cases (25).

All statistical analyses were performed with the Statistical Package for the Social Sciences (SPSS), version 10.0.

\section{Results}

Demographic data and clinical findings at the time of initial evaluation for the two treatment groups are presented in Table 1. The patients treated with steroids alone were older, more frequently males, and $50 \%$ had renal insufficiency at the time of the diagno-

Table 1. Demographic data and clinical findings at the time of initial evaluation for patients with nephrotic syndrome in the two treatment groups.

\begin{tabular}{lcrrrr}
\hline Groups & Age & $\begin{array}{c}\text { Gender } \\
\text { (M/F) }\end{array}$ & $\begin{array}{c}\text { Renal } \\
\text { failure }\end{array}$ & Hypertension & $\begin{array}{r}\text { Follow-up } \\
\text { (months) }\end{array}$ \\
\hline Prednisone & $24.0 \pm 12.0^{*}$ & $19 / 5$ & $12(50.0)^{*}$ & $7(29.2)$ & $51.5 \pm 59.1^{*}$ \\
Prednisone + cyclophosphamide & $14.2 \pm 12.1$ & $15 / 15$ & $8(26.7)$ & $7(23.3)$ & $113.8 \pm 88.6$ \\
Total & $18.6 \pm 12.9$ & $34 / 20$ & $20(37.0)$ & $14(25.9)$ & $86.1 \pm 82.4$ \\
\hline
\end{tabular}

Data are reported as means $\pm S D$ or number of patients. The values given in parentheses are percent. $M=$ male; $F=$ female. ${ }^{*} \mathrm{P}<0.01$ for prednisone compared to prednisone + cyclophosphamide (Student $t$-test). 
sis of nephrotic syndrome. The follow-up of this group of patients was also significantly shorter. Fifteen patients $(68 \%)$ treated with prednisone and $14(50 \%)$ treated with cyclophosphamide in combination with prednisone had a mild to moderate degree of interstitial fibrosis.

The response to the treatments is pre-

Table 2. Response to treatment of nephrotic syndrome with immunosuppressive agents.

$\begin{array}{lcc}\begin{array}{l}\text { Response to } \\ \text { treatment }\end{array} & \text { Prednisone } & \begin{array}{c}\text { Prednisone }+ \\ \text { cyclophosphamide }\end{array} \\ \text { Complete } & 11(20.4) & 8(26.7) \\ \text { Partial } & 8(14.8) & 6(20.0) \\ \text { Resistant } & 30(55.5) & 16(53.3) \\ \text { Dependent } & 5(9.3) & 0(00.0) \\ \text { Total } & 54(100) & 30(100)\end{array}$

Data are reported as number of patients and percent values are given in parentheses.

Table 3. Response to treatment and degree of interstitial fibrosis in patients with prednisone-resistant nephrotic syndrome.

\begin{tabular}{|c|c|c|c|c|c|c|}
\hline \multirow[t]{3}{*}{ Interstitial fibrosis } & \multicolumn{6}{|c|}{ Response to treatment } \\
\hline & \multicolumn{3}{|c|}{ Prednisone } & \multicolumn{3}{|c|}{ Prednisone + cyclophosphamide } \\
\hline & Complete & Partial & Resistant & Complete & Partial & Resistant \\
\hline 0 & 3 & 5 & 6 & 7 & 2 & 8 \\
\hline 1 & 1 & 2 & 4 & 3 & 2 & 6 \\
\hline 2 & 1 & & & & & \\
\hline Total & 5 & 7 & 10 & 10 & 4 & 14 \\
\hline
\end{tabular}

There was no statistical significance between the results for prednisone compared to prednisone + cyclophosphamide $\left(\chi^{2}\right.$ test; $\left.P>0.05\right)$.

Table 4. Effect of the response to treatment on the progression of renal disease in patients with focal segmental glomerulosclerosis.

\begin{tabular}{|c|c|c|c|c|c|c|}
\hline \multirow{3}{*}{$\begin{array}{l}\text { Progression of } \\
\text { renal disease }\end{array}$} & \multicolumn{6}{|c|}{ Response to treatment } \\
\hline & \multicolumn{3}{|c|}{ Prednisone } & \multicolumn{3}{|c|}{ Prednisone + cyclophosphamide } \\
\hline & Complete & Partial & Resistant & Complete & Partial & Resistant \\
\hline Absent & 5 & 4 & 7 & 8 & 5 & 12 \\
\hline Present & 0 & 3 & 5 & 0 & 1 & 4 \\
\hline Total & 5 & 7 & 12 & 8 & 6 & 16 \\
\hline
\end{tabular}

sented in Table 2: complete remission was recorded in $20.4 \%$ and partial remission in $14.8 \%$ of the patients treated with prednisone and in 26.7 and $20.0 \%$, respectively, of the patients treated with cyclophosphamide + prednisone. Remissions were less frequent among children than among adults for prednisone (23.3 vs 50.0\%; $\mathrm{P}=0.04)$, but there was no statistical difference for prednisone plus cyclophosphamide. Four patients (2 treated with prednisone and 2 treated with cyclophosphamide in conjunction with prednisone) who were resistant to the immunosuppressive treatment subsequently developed a clinical course characterized by persistent non-nephrotic proteinuria. In the 50 patients who had the renal interstitium examined, there was no association between the degree of interstitial fibrosis and the response to therapy (Table 3). A decrease in the frequency of relapses was observed in all 6 patients with frequently relapsing nephrotic syndrome. Despite mild signs of hypercortisolism, no patient presented an adverse reaction requiring discontinuation of treatment.

The influence of the response to therapy on the progression of renal disease is shown in Table 4 and it was more frequent among patients resistant to therapy, although 1 patient who initially showed complete remission of nephrotic syndrome during treatment with prednisone progressed to persistent nonnephrotic proteinuria and mild renal insufficiency.

Persistent nephrotic syndrome and progressive renal insufficiency were more frequent among patients treated with prednisone alone than among patients treated with prednisone plus cyclophosphamide (Table 5). The renal survival rate (Figure 1) of the group was $88 \%$ at 5 years, $75 \%$ at 10 and $75 \%$ at 15 years. At the time of final clinical evaluation, 18 of 54 patients had hypertension. Seven patients with hypertension were treated with angiotensin converting enzyme inhibitors (ACEi). Nine patients (16.6\%) had 
reached end-stage renal disease, corresponding to $25 \%$ of the patients treated with prednisone alone and $10 \%$ of the patients treated with prednisone + cyclophosphamide.

\section{Discussion}

In recent years prednisone has became the treatment of choice for focal segmental glomerulosclerosis and its therapeutic response has been recognized as a predictor of long-term prognosis $(7,12,16,26-29)$. In contrast, the persistence of nephrotic syndrome portends a reserved prognosis $(15,30)$. Since spontaneous remission of focal segmental glomerulosclerosis is rare $(7,12-14)$ and an improved prognosis is associated with the remission of nephrotic syndrome, it is in the group of patients with steroid-resistant focal segmental glomerulosclerosis that cytotoxic drugs have been used in combination with prednisone.

In the present series, remission of the proteinuria associated with prednisone was documented in $35.2 \%$ of the patients, and was more frequent in adults than in children. This finding was not unexpected since only nephrotic children resistant to steroids or with atypical manifestations are submitted to renal biopsies in our service. In the present study steroid resistance was defined as persistence of proteinuria in the nephrotic range over a period of 8 weeks of daily steroid therapy. It is possible that other patients might experience remission of proteinuria with a more prolonged course of prednisone therapy (9). Recently, Ponticelli et al. (19) showed that patients treated for more than 16 weeks attained complete remission more frequently than patients treated for 16 weeks or less. Remission of proteinuria, either complete $(26.7 \%)$ or partial

Table 5. Clinical course of patients with nephrotic syndrome in the two treatment groups.

\begin{tabular}{lrrrrr}
\hline \multirow{2}{*}{ Groups } & \multicolumn{2}{c}{ Clinical course } & Progression ESRD \\
\cline { 2 - 4 } & & Remission & $\begin{array}{c}\text { Persistent } \\
\text { proteinuria }\end{array}$ & $\begin{array}{c}\text { Persistent } \\
\text { nephrotic syndrome }\end{array}$ & \\
\hline Prednisone & $8(33.3)$ & $4(16.7)$ & $12(50.0)$ & $8(33.3)$ & $6(25.0)$ \\
$\begin{array}{l}\text { Prednisone }+ \\
\text { cyclophosphamide }\end{array}$ & $17(56.7)$ & $3(10.0)$ & $10(33.3)$ & $5(16.7)$ & $3(10.0)$ \\
Total & $25(46.3)$ & $7(13.0)$ & $22(20.7)$ & $13(24.0)$ & $9(16.6)$
\end{tabular}

Data are reported as number of patients and percent values are given in parentheses. ESRD = end-stage renal disease.

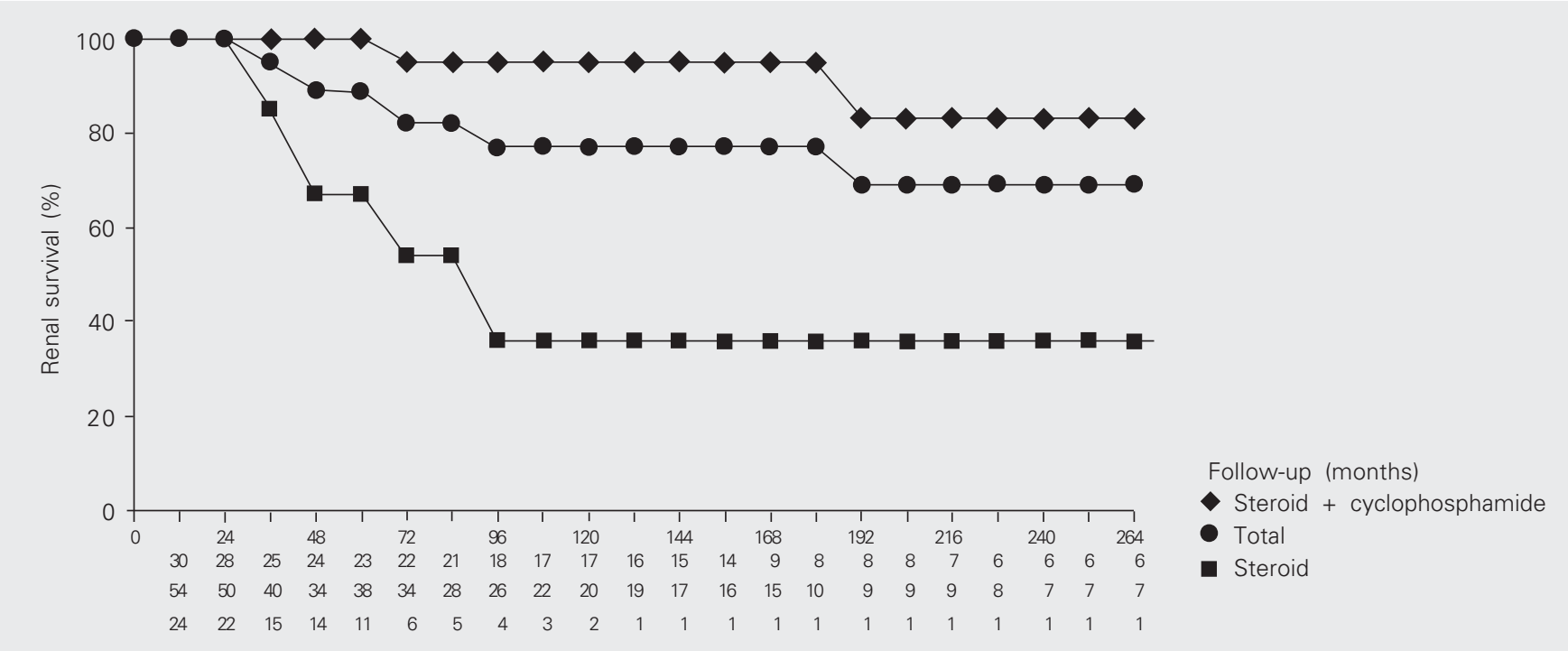

Figure 1. Renal survival of patients with focal segmental glomerulosclerosis and nephrotic syndrome treated with immunosuppressive agents. Number of patients reported at bottom of figure. 
(20.0\%), was demonstrated in $46.7 \%$ of the patients, treated with cyclophosphamide in combination with prednisone, resulting in more sustained remission and preservation of renal function. Although cyclophosphamide did not completely prevent relapses, it was associated with a clinical course characterized by remission of the nephrotic syndrome: no patient with complete remission and $16.7 \%$ of those with partial remission after treatment with prednisone in combination with cyclophosphamide subsequently evolved persistently nephrotic syndrome. The addition of cyclophosphamide, however, was less effective in patients with prednisoneresistant nephrotic syndrome, since remission was observed in $33.3 \%$ of them, a rate similar to that observed by others (31). Nevertheless, in the present series, remission of proteinuria was associated with preservation of renal function, with all patients with complete remission of nephrotic syndrome and 3 of the 8 patients with partial remission continuing to have normal renal function at the time of final evaluation. Banfi et al. (16) and Ponticelli et al. (19) also concluded that achieving complete or partial remission was a strong clinical predictor of outcome in patients with focal segmental glomerulosclerosis and nephrotic syndrome.

Unexpectedly, the preservation of renal function was more frequently observed among the patients treated with cyclophosphamide in combination with prednisone than with prednisone alone. This finding could not be related to the degree of interstitial fibrosis, even though the small number of patients in the present series does not permit us to reach a definitive conclusion. However, it could be a consequence of a selection bias since renal insufficiency at initial evaluation, a predictor of poor outcome, was more frequent in the group of patients treated with prednisone alone than in the group treated with both drugs together. Also, the use of ACEi and dietary protein restriction, which are well-known reducers of urinary protein excretion in glomerular diseases, and the current levels of systolic blood pressure (32) were not controlled. An ACEi was used in $40 \%$ of hypertensive patients, evenly distributed through both treatment groups.

Tarshish et al. (21), in a prospective study, found no additional benefit for renal function after the treatment of children with cyclophosphamide plus prednisone. In contrast to this observation but consistent with our findings, Geary et al. (20), Tufro-McReddie et al. (33), and Tune et al. (34) found progression to renal failure to be less frequent in children treated with cyclophosphamide, and Banfi et al. (16) and Ponticelli et al. (19) found the same to be true in adults. Better preservation of renal function was also reported by Cattran et al. (18) in patients treated with cyclosporine.

Equally important is the fact that the treatment regimens were well tolerated: despite mild hypercortisolism, no patient presented intolerance or a toxic reaction to cyclophosphamide. Indeed, at the dosages used in the present trial, a toxic reaction to cyclophosphamide would have been unexpected.

Although male patients were more frequent in the group treated with prednisone and prednisone plus cyclophosphamide, gender was not significantly correlated with outcome in the treatment groups or even in the total group of patients. Nevertheless, the small number of patients reaching advanced renal failure could account for the lack of a correlation between gender and end-stage renal disease in the present study. Chitalia et al. (28), using a multivariate model, and Korbet (29) and Rydel et al. (12), using univariate analysis, also could not detect a correlation between gender and progression of focal segmental glomerulosclerosis. Although resistance to prednisone was more frequent among children than among adults, this finding may have been related to a selection bias. Indeed, except for Newman et al. (13), differences between adults and chil- 
dren have been reported infrequently.

Cyclosporine (18) and mycophenolate mofetil (35) have been used in the treatment of focal segmental glomerulosclerosis. So far, no comparative study has been published although Cattran et al. (18) reported remission of proteinuria in $70 \%$ of the patients with steroid-resistant nephrotic syndrome treated with cyclosporine, a greater proportion than that achieved in the present study using cyclophosphamide. The beneficial effects afforded by the use of ACEi in the treatment of proteinuric nephropathies, including focal segmental glomerulosclerosis, also suggest that they can be used as supportive treatment for this glomerular disease (36-38) although definite evidence that
ACEi alter the natural course of focal segmental glomerulosclerosis is still lacking (39). The role of other agents used in the treatment of focal segmental glomerulosclerosis is still poorly defined (40).

Although open-label and non-randomized, the therapeutic regimens were standardized. The present trial showed that cyclophosphamide in combination with steroids could be a reasonable choice in the treatment of steroid-resistant focal segmental glomerulosclerosis. Randomized placebo-controlled trials are needed to define the benefit of cyclophosphamide or other cytotoxic agents or of ACEi in the long-term treatment of focal segmental glomerulosclerosis.

\section{References}

1. D'Agati $V$ (1994). The many masks of focal segmental glomerulosclerosis. Kidney International, 46: 1223-1241.

2. Haas M, Meehan SM, Karrison TG \& Spargo BH (1997). Changing etiologies of unexplained adult nephrotic syndrome: a comparison of renal biopsy findings from 1976-1979 and 1995-1997. American Journal of Kidney Diseases, 30: 621-631.

3. Srivastava T, Simon SD \& Alon US (1999). High incidence of focal segmental glomerulosclerosis in nephrotic syndrome of childhood. Pediatric Nephrology, 13: 13-18.

4. Aviles DH, Irwin KC, Dublin LS \& Vehaskari VM (1999). Aggressive treatment of severe idiopathic focal segmental glomerulosclerosis. Pediatric Nephrology, 13: 298-300.

5. Beaufils H, Alphonse JC, Guedon J \& Legrain M (1978). Focal glomerulosclerosis: Natural history and treatment. Nephron, 21: 7585

6. Cameron JS (1996). The enigma of focal segmental glomerulosclerosis. Kidney International, 50 (Suppl 57): S119-S131.

7. Cattran DC \& Rao P (1998). Long-term outcome in children and adults with classic focal segmental glomerulosclerosis. American Journal of Kidney Diseases, 32: 72-79.

8. Korbet SM, Schwartz MM \& Lewis EJ (1994). Primary focal segmental glomerulosclerosis: clinical course and response to therapy. American Journal of Kidney Diseases, 23: 773-783.

9. Matalon A, Valeri A \& Appel GB (2000). Treatment of focal segmental glomerulosclerosis. Seminars in Nephrology, 20: 309-317.

10. Mongeau JG, Robitaille PO, Clermont MJ, Merouani A \& Russo P (1993). Focal segmental glomerulosclerosis (FSG) 20 years later. From toddler to grown up. Clinical Nephrology, 40: 1-6.

11. Rennert WP, Kala UK, Jacobs D, Goetsch S \& Verhaat S (1999). Pulse cyclophosphamide for steroid-resistant focal segmental glomerulosclerosis. Pediatric Nephrology, 13: 113-116.

12. Rydel JJ, Korbet SM, Borok RZ \& Schwartz MM (1995). Focal segmental glomerular sclerosis in adults: Presentation, course and response to treatment. American Journal of Kidney Diseases, 25: 534-542.

13. Newman WJ, Tisher CC, McCoy RC, Gunnells JC, Krueger RP, Clapp JR \& Robinson RR (1976). Focal glomerular sclerosis: contrasting clinical patterns in children and adults. Medicine, 55: 67-87.

14. Pei Y, Cattran D, Delmore T, Katz A, Lang A \& Rance P (1987). Evidence suggesting under-treatment in adults with idiopathic focal segmental glomerulosclerosis. American Journal of Medicine, 82: 938-944.

15. Yoshikawa N, Ito H, Akamatsu R, Matsuyama S, Hasegawa O, Nakahara C \& Matsuo T (1986). Focal segmental glomerulosclerosis with and without nephrotic syndrome in children. Journal of Pediatrics, 109: 65-70.

16. Banfi G, Moriggi M, Sabadini E, Fellin G, D'Amico G \& Ponticelli C (1991). The impact of prolonged immunosuppression on the outcome of idiopathic focal segmental glomerulosclerosis. A collaborative retrospective study. Clinical Nephrology, 36: 53-59.

17. Burgess E (1999). Management of focal segmental glomerulosclerosis: evidence-based recommendations. Kidney International, 55 (Suppl 70): S26-S32.

18. Cattran DC, Appel GB, Hebert LA, Hunsicker LG, Pohl MA, Hoy WE, Maxwell DR \& Kunis CL (1999). A randomized trial of cyclosporine in patients with steroid-resistant focal segmental glomerulosclerosis. Kidney International, 56: 2220-2226.

19. Ponticelli C, Villa M, Banfi G, Cesana B, Pozzi C, Pani A, Passerini $P$, Farina M, Grassi C \& Baroli A (1999). Can prolonged treatment improve the prognosis in adults with focal segmental glomerulosclerosis? American Journal of Kidney Diseases, 34: 618-625.

20. Geary DF, Farine M, Thorner P \& Baumal R (1984). Response to cyclophosphamide in steroid-resistant focal segmental glomerulosclerosis: a reappraisal. Clinical Nephrology, 22: 109-113.

21. Tarshish P, Tobin JN, Bernstein J \& Edelman Jr CM (1996). Cyclophosphamide does not benefit patients with focal segmental glo- 
merulosclerosis. A report of the International Study of Kidney Disease in Children. Pediatric Nephrology, 10: 590-593.

22. Churg J, Bernstein J \& Glassock RJ (1995). Renal Disease. Classification and Atlas of Glomerular Diseases. 2nd edn. Igaku-Shoin, New York

23. D'Agati V (2003). Pathologic classification of focal segmental glomerulosclerosis. Seminars in Nephrology, 23: 117-134.

24. Kaplan EL \& Meier P (1958). Nonparametric estimation for incomplete observations. American Statistical Association Journal, 53: 457-481.

25. Armitage P \& Berry G (1994). Statistical Methods in Medical Research. 3rd edn. Blackwell Science, Oxford, UK.

26. Arbus GS, Poucell S, Bacheyie GS \& Baumal R (1982). Focal segmental glomerulosclerosis with idiopathic nephrotic syndrome: Three types of clinical response. Journal of Pediatrics, 101: 40-45.

27. Chan PCK, Chan KW, Cheng IKP \& Chan MK (1991). Focal sclerosing glomerulopathy: Risk factors of progression and optimal mode of treatment. International Urology and Nephrology, 239: 619-629.

28. Chitalia VC, Wells JE, Robson RA, Searle M \& Lynn KL (1999). Predicting renal survival in primary focal segmental glomerulosclerosis from the time of presentation. Kidney International, 56: 2236 2242.

29. Korbet SM (1999). Clinical picture and outcome of primary focal segmental glomerulosclerosis. Nephrology, Dialysis, Transplantation, 14 (Suppl 3): 68-73.

30. Velosa JA, Holley KE, Torres VE \& Offord KP (1983). Significance of proteinuria on the outcome of renal function in patients with focal segmental glomerulosclerosis. Mayo Clinic Proceedings, 58: 568577.

31. Ponticelli C \& Passerini P (2003). Other immunosuppressive agents for focal segmental glomerulosclerosis. Seminars in Nephrology, 23: $242-248$

32. Jafar TH, Stark PC, Schmid CH, Landa M, Maschio G, de Jong P, de Zeeuw D, Shahinfar S, Toto R \& Levey A (2003). Progression of chronic kidney disease: The role of blood pressure control, proteinuria, and angiotensin-converting enzyme inhibition. A patient-level meta-analysis. Annals of Internal Medicine, 139: 244-252.

33. Tufro-McReddie A, Alvarez E, Arrizurieta E \& Repetto H (1992). Focal glomerulosclerosis in children: an Argentinean experience. Pediatric Nephrology, 6: 158-161.

34. Tune BM, Kirpekar R, Sibley RK, Reznik VM, Griswold WR \& Mendoza AS (1995). Intravenous methylprednisolone and oral alkylating agent therapy of prednisone-resistant pediatric focal segmental glomerulosclerosis: a long-term follow-up. Clinical Nephrology, 43: 84-88

35. Choi MJ, Eustace JÁ, Gimenez LF, Atta MG, Scheel PJ, Sothinathan $R$ \& Briggs WA (2002). Mycophenolate mofetil treatment of primary glomerular diseases. Kidney International, 61: 1098-1114.

36. Ruggenenti P, Perna A, Gherardi G, Benini R \& Remuzzi G (2000). Chronic proteinuric nephropathies: outcomes and response to treatment in a prospective cohort of 352 patients with different patterns of renal injury. American Journal of Kidney Diseases, 35: 11551165.

37. Crenshaw G, Bigles S, Salem M \& Crook ED (2000). Focal segmental glomerulosclerosis in African-Americans: effects of steroids and angiotensin converting enzyme inhibitors. American Journal of the Medical Sciences, 319: 320-325.

38. Huissoon A, Meehan S \& Keogh J (1991). Reduction of proteinuria with captopril therapy in patients with focal segmental glomerulosclerosis and IgA nephropathy. Irish Journal of Medical Science, 160: 319-321.

39. Korbet SM (2003). Angiotensin antagonists and steroids in the treatment of focal segmental glomerulosclerosis. Seminars in $\mathrm{Ne}$ phrology, 23: 219-228.

40. Pesserini P \& Ponticelli C (2001). Treatment of focal segmental glomerulosclerosis. Current Opinion in Nephrology and Hypertension, 10: 189-193. 